292 Basset: Wirkung v. Chlorpikrin u. Chloroform auf essigsaures Kali.

\title{
XXIX.
}

\section{Ueber die Wirkung von Chlorpikrin und Chloroform auf essigsaures Kali.}

\author{
Von \\ Henry Basset.
}

(Journ. of the chem. society. Ser, 2, vol. 3, p. 31.)

Haben auch die folgenden Versuche nicht zur Auffindung einer neuen Substanz gefübrt, so sind sie doch nicht obne Interesse, theils als weitere Beweise für die Art der Wirkung jener Körper, theils da sie die Ansicht bestätigen, dass ihre Constitution aus dem Verbalten ihrer Aethylderivate zu erklären sei, indem die in ihnen enthaltenen $\mathrm{C}$ und CH Atome eine entschiedene Neigung haben, statt der vieroder dreistomigen Alkoholderivate die entsprechende Kohlen- and Ameisensäure zu bilden.

Chlorpikrin zersetzt sich mit geschmolzenem essigsauren Kali und Alkohol in einem verschlossenen Gefäss auf $100^{\circ}$ erhitzt, sehr rasch ohne Gasentwicklung, unter Bildung von Chlorkalium und einer sauren Lösung, aus welcher sich beim Abkühlen ein krystallisirtes Salz in bedeutender Menge abscheidet. Zuerst wurde auf 4 Aequivalente essigsaures Kali ein Aequivalent Chlorpikrin genommen, da aber dabei stets ein Theil des letzteren unzersetzt blieb, so wurden schliesslich 9 Aequivalente essigsaures Kali angewendet, wobei fast alles Chlorpikrin verbraucht wurde.

Die alkoholische Lösung wurde noch heiss von dem Chlorkalium abfiltrirt und setzte theils freiwillig, theils nach dem Eindampfen eine Menge nadelförmiger Krystalle ab. Das Destillat besass einen deutlichen Geruch nach Essigäther und reagirte sauer.

Aus der Analyse des Salzes ergab sich, dass dasselbe doppelt essigsaures Kali war. Demnach geht die Zersetzung nach folgender Gleichung vor sich:

$$
\begin{gathered}
\qquad N \theta_{2} \mathrm{Cl}_{3}+9 \epsilon_{2} \mathrm{H}_{3} \mathrm{~K}_{2}+3 \epsilon_{2} \mathrm{H}_{8} \theta= \\
=3 \mathrm{KCl}+\mathrm{KN} \theta_{2}+\mathrm{K}_{2} \epsilon \theta_{3}+3 \epsilon_{4} \mathrm{H}_{8} \Theta_{2}+3 \epsilon_{4} \mathrm{H}_{7} \mathrm{~K} \theta_{4} . \\
\text { Essigäther. Doppelt essig. }
\end{gathered}
$$


Auch salpetrigsaures und kohlensaures Kali konnten deutlich mit den gewöbnlichen Reagentien nachgewiesen werden.

Chloroform wurde bei derselben Behandlung nur schwach angegriffen, stieg aber die Temperatur auf $125^{\circ}$, so bildete sich eine reichliche Menge Chlorkalium, und nach drei bis vier Stunden war die Reaction beendigt. Beim Oeffnen der Röhre entwich etwas Kohlenoxydgas. Das beim Destilliren zurückbleibende Salz war mit dem durch Chlorpikrin erhaltenen völlig identisch. In diesem Falle entspricht der Reaction die Gleichung

$$
\begin{gathered}
\epsilon \mathrm{HCl}_{3}+6 \epsilon_{2} \mathrm{H}_{3} \mathrm{~K}_{2}+2 \epsilon_{2} \mathrm{H}_{6} \boldsymbol{\theta}= \\
=3 \mathrm{KCl}+\epsilon \mathrm{HK} \boldsymbol{\theta}_{2}+2 \epsilon_{4} \mathrm{H}_{8} \boldsymbol{\theta}_{4}+2 \epsilon_{4} \mathrm{H}_{7} \mathrm{~K} \boldsymbol{\theta}_{4} .
\end{gathered}
$$

Die Ameisensäure wurde durch Reduction von Quecksilberchlorid und die Bildung von Kohlenoxyd beim Erwärmen mit Schwefelsäure in der Mutterlauge des doppeltessigsauren Kalis nachgewiesen.

Beim Erhitzen eines Theils Chlorpikrin mit drei Theilen Anilin bis $145^{\circ}$ trat eine lebbafte Reaction unter Stickstoffentwicklung ein. Siedendes Wasser zog aus dem Product eine Substanz aus, der von $\mathrm{H}$ of $\mathrm{m}$ a $\mathrm{n}$ ans dem Vierfachcblorkohlenstoff erbaltenen ähnlich, ausserdem löst sich das Hydrochlorat einer festen Base, die nach der Analyse Kohlenstoff-Triphenyl-Triamin war.

\section{XXX. \\ Ueber eine neue allgemeine Eigenschaft der Aether.}

Von

H. Gal.

(Compt. rend. t. 59, p. 1049.)

Eine der allgemeinsten und merkwürdigsten Eigenschaften der Aether ist ohne Zweifel die Zersetzung in Alkohol und die entsprechende Săure, welche sie durch Al- 